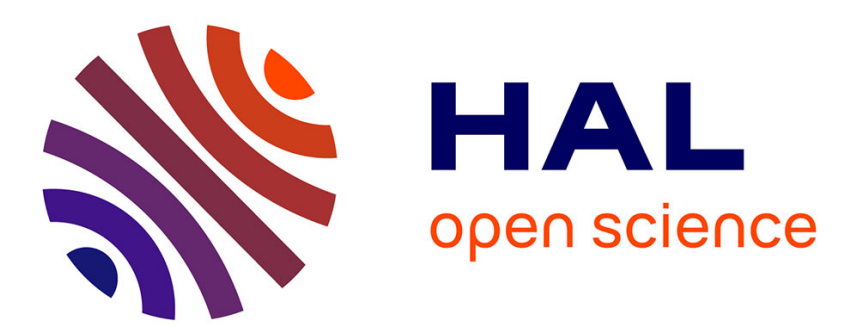

\title{
Validation of self-reported occupational noise exposure in participants of a French case-control study on acoustic neuroma
}

Isabelle Deltour, Amélie Massardier-Pilonchery, Brigitte Schlehofer, Klaus Schlaefer, Martine Hours, Joachim Schuz

\section{To cite this version:}

Isabelle Deltour, Amélie Massardier-Pilonchery, Brigitte Schlehofer, Klaus Schlaefer, Martine Hours, et al.. Validation of self-reported occupational noise exposure in participants of a French case-control study on acoustic neuroma. International Archives of Occupational and Environmental Health, 2019, 92 (7), pp. 991-1001. 10.1007/s00420-019-01427-2 . hal-02476217

\section{HAL Id: hal-02476217 \\ https://hal.science/hal-02476217}

Submitted on 28 May 2021

HAL is a multi-disciplinary open access archive for the deposit and dissemination of scientific research documents, whether they are published or not. The documents may come from teaching and research institutions in France or abroad, or from public or private research centers.
L'archive ouverte pluridisciplinaire HAL, est destinée au dépôt et à la diffusion de documents scientifiques de niveau recherche, publiés ou non, émanant des établissements d'enseignement et de recherche français ou étrangers, des laboratoires publics ou privés. 


\section{Validation of self-reported occupational noise exposure in participants}

\section{of a French case-control study on acoustic neuroma}

Authors: Isabelle Deltour ${ }^{a}$, Amélie Massardier-Pilonchery, ${ }^{b, c}$, Brigitte Schlehofer, $^{a, d}$, Klaus

Schlaefer ${ }^{d}$, Martine Hours ${ }^{b}$, Joachim Schüz ${ }^{a}$.

a Section of Environment and Radiation, International Agency for Research on Cancer, 150, Cours Albert Thomas 69372 Lyon Cedex 08 France Lyon, France

b University Claude Bernard Lyon 1 and IFSTTAR, Transport Work and Environmental Epidemiology Research and Surveillance Unit - UMRESTTE (UMR 14T9405), 8 Avenue Rockefeller, 69373 Lyon Cedex 08, France

${ }^{\mathrm{c}}$ Hospices Civils de Lyon, Lyon, France

dUnit of Environmental Epidemiology, German Cancer Research Centre, Heidelberg, Germany Corresponding author: Isabelle Deltour (deltouri@iarc.fr) phone: + 33472738406 Fax : 3347273 8575 mobile: + 33675534604

Short title: Self-reported occupational noise exposure

Declarations of interest: none

Total words: 4503

KEYWORDS: Occupational self-reported noise exposure, data validity, exposure misclassification, recall bias, expert assessment, case-control study

Funding

This work was supported by funding from the French Agency for Food, Environmental and Occupational Health \& Safety (ANSES) 'Programme national de recherche Environnement-Santé Travail' (contract EST 11-74).

The INTERPHONE study was supported by funding from the European Fifth Framework Program, 'Quality of Life and Management of Living Resources' (contract QLK4-CT-1999901563) and the International Union against Cancer (UICC). The UICC received funds for this purpose from the Mobile Manufacturers' Forum and GSM Association. Provision of funds to the INTERPHONE study investigators via the UICC was governed by agreements that guaranteed INTERPHONE's complete scientific independence. The terms of these agreements are publicly available at http://www.iarc.fr/en/research-groups/RAD/RCAd.html. 
Additional funding for the Interphone study in France was provided by l'Association pour la Recherche sur le Cancer (ARC) [Contrat No. 5142] and three network operators (Orange, SFR, Bouygues Télécom). The funds provided by the operators represented $5 \%$ of the total cost of the French study and were governed by contracts guaranteeing the complete scientific independence of the investigators.

\section{Acknowledgements}

The authors alone are responsible for the views expressed in this article and they do not necessarily represent the views, decisions or policies of the institutions with which they are affiliated.

The authors thank the anonymous reviewer who provided useful comments on an earlier version of the manuscript, and Dr Graham Byrnes for useful discussions about these.

The authors acknowledge the Interphone Study Group and Dr E Cardis, PI, for the development of the questionnaire.

The French Interphone team would like to thank the French fieldwork team: Mary-Pierre Herrscher, Fatima Lamri, Agnès Boidart, Hélène Gire, Juliette Krassilchik, Judith Lenti, Delphine Maillac, Frédérique Sonnet, Flore Taguiev, Julie Frantz, France Castay, Florian Gay, for their excellent work; all the hospital services who assisted us in the ascertainment of cases: Lyon - Centre Hospitalier Lyon Sud (Prof. Dubreuil), Hôpital Neurologique Pierre Wertheimer (Prof. Fisher, Prof. Vallée, Prof. Bret, Prof. Sindou, Prof. Deruty); Paris - Hôpital Foch (Prof. Chabolle), Hôpital Beaujon (Prof. Sterkers, Dr Bouccara), Hôpital Lariboisière (Prof. Tran Ba Huy), Marseille - Hôpital de la Timone (Prof. Peragut, Dr Regis), as well as all those in the departments of medical information and all the hospital personnel, particularly the secretaries and the staff in the medical archives, whose assistance proved essential to the success of the project.

\section{Declaration of interest: none}




\section{ABSTRACT (215)}

Objectives: To validate self-reported occupational loud noise exposure against expert evaluation of noise levels in a French case-control study on acoustic neuroma. To estimate the impact of exposure misclassification on risk estimation.

Methods: Noise levels were evaluated in 1006 jobs held by 111 cases and 217 population controls by an expert. Case-control differences in self-reporting were analyzed with logistic models. Sensitivity, specificity, positive and negative predictive values, and observed agreement of the self-reports were computed relative to the expert evaluation. They were used to calibrate the odds ratio (OR) between lifetime ever occupational loud noise exposure and the risk of acoustic neuroma, without adjustment for measurement error of the expert assessments.

Results: Cases reported noise levels in individual jobs closer to the expert assessment than controls, but the case-control difference was small for lifetime exposures. For expert rated exposure of 80 $d B(A)$, reporting of individual jobs by cases was more sensitive (54\% in cases, $37 \%$ in controls) whereas specificity (91\% in cases, $93 \%$ in controls) and observed agreement ( $82 \%$ in cases, $81 \%$ in controls) were similar. When lifetime exposure was considered, sensitivity increased ( $76 \%$ in cases, $65 \%$ in controls) while cases specificity decreased (84\%). When these values were used to calibrate self-reports for exposure misclassification compared to expert evaluation at $80 \mathrm{~dB}(\mathrm{~A})$, the crude $O R$ of 1.7 was reduced to 1.3 .

Conclusions: Despite of relatively accurate reporting of loud noise, the impact of the calibration on the OR was non-negligible. 


\section{INTRODUCTION}

Noise is unwanted sound in a given place, time and condition. Occupational noise exposures are encountered in many industrial sectors such as construction, agriculture, manufacturing utilities, and transport (Basner et al. 2014; Lie et al. 2016). The large Medical Monitoring Survey of Professional Risks ("SUMER") examined working conditions in France and assessed employees' exposure to harmful working conditions. The study estimated that $19 \%$ of the French workers encountered hazardous levels of noise in 2010 (European Foundation for the Improvement of Living and Working Conditions 2013; Hormozi et al. 2017).

Studies to investigate the relationship between loud noise exposure and acoustic neuroma recurred since the 1980s with inconsistent findings (Adelman 1983; Edwards et al. 2006; Edwards et al. 2007; Fisher et al. 1994; Fisher et al. 2014; Hours et al. 2009; Miller et al. 1981; Preston-Martin et al. 1989; Schlehofer et al. 2007); in these, noise exposures have been obtained from self-reports from study participants or from job exposure matrices (JEM). However, only few investigations exist to validate self-reported noise exposure (Ahmed et al. 2004; Fisher et al. 2014; Schlaefer et al. 2009). In retrospective epidemiological observational studies, questionnaires/interviews are sometimes the only feasible means to obtain information about the exposures of interest. It has been recommended that exposure assessment methods be compared, to choose the most appropriate and/or avoid overstating confidence in the risk estimates (Lash et al. 2009; Lash et al. 2014; McGuire et al. 1998).

The Interphone Study was conducted as a multi-centre case-control study in 13 countries between 1999 and 2004. The main goal was to explore whether radio-frequency electromagnetic fields from mobile phone use were associated with different types of adult brain tumors, namely glioma, meningioma or acoustic neuroma. In addition, information was collected on other possible risk factors and life events, like ionizing radiation, and medical history. For acoustic neuroma cases and their controls, detailed lifelong loud noise exposure was specifically elicited, and in most countries, a lifelong occupational history was also recorded (Cardis et al. 2007). The present validation study was 
performed based on the French acoustic neuroma Interphone study using the expertise of the UMRESTTE, Lyon, a French laboratory specialized in occupational noise, following a validation of the German Interphone component (Schlaefer et al. 2009). Since 1970, this occupational medicine department of the University of Lyon investigates the exposure to noise in industrial jobs of the Eastern part of France. It has the mandate to evaluate noise hazards and occupational hearing loss.

The aims of this study were to quantify the validity of the self-reported occupational loud noise exposure compared to expert rating for noise exposure at work, and to explore the impact of the misclassification on the risk estimation.

\section{MATERIAL AND METHODS}

\section{Study population}

This project has been conducted within the French acoustic neuroma cases and controls of the Interphone Study, described elsewhere (Cardis et al. 2007; Hours et al. 2007). Briefly, eligible cases were all patients with a schwannoma of the acoustic nerve (ICD-9 code 225.1 or ICD-10 code D33.3, and ICD-O topography code C72.4 and morphology code 9560/0) diagnosed between 1 June 2000 and 31 August 2003 residing in Ile-de-France (administrative region around Paris) or in Grand-Lyon (administrative region around Lyon). Cases were ascertained from all hospital departments of neurology, neurosurgery, and otorhinolaryngology in the urban area of Lyon, and from approximately half of the major departments of these specialties of Paris. The radiotherapy department of La Timone hospital in Marseille, specialized in radiation therapy of head tumors, also notified 9 cases residing in Paris. Completeness of ascertainment was thoroughly checked for the participating departments. All diagnoses were either histologically confirmed or resulted from unequivocal diagnostic imaging. For each case, two individually matched controls were selected from the electoral lists. The matching variables were age (within 5 years), gender, and region of residence at the time of the case diagnosis. 
A total of 140 neuroma cases and 290 control subjects were identified. Participation rate was $77 \%$ for cases and $74 \%$ for control subjects (Hours et al. 2009). All acoustic neuroma patients and their matched controls were asked for detailed information on noise exposure by computer-assisted personal interviews (CAPI). In addition, information on socio-demographics characteristics, lifetime occupational history (all jobs held for at least one year), medical conditions, and on the use of wireless technologies was collected. Data were collected during face-to-face interviews with the study subject either in hospital, at home or at any other convenient location (exceptionally, by phone $\mathrm{N}=28$ ); interviewers were therefore not blinded to the case or control status of the study subject. As far as possible, the same interviewer interviewed the case and his matched controls.

\section{Exposure assessment}

Concerning occupational loud noise exposure, all interviewees first answered a screening question: "Would you say you have ever been exposed to loud noise at work?" If participants confirmed, all individual jobs reported to be noise exposed were identified in the previously recorded full occupational history. Additional information was collected on starting and ending dates of the noise exposure; and whether hearing protection was provided and used.

Expert rating of noise exposure was based, in blind condition to the case/control status, on the job titles, the company name, the job tasks and the employment period of the individual jobs reported. Individual job periods ( $\mathrm{N}=1006$ ) have been assigned a noise level, evaluated on the continuous scale of decibel with acoustic weighting $(\mathrm{dB}(\mathrm{A})$, where the weighting accounts for the relative loudness perceived by the human ear). Job periods were categorized in three groups, depending on the noise average level: $<80 \mathrm{~dB}(\mathrm{~A}), 80-84 \mathrm{~dB}(\mathrm{~A}), \geq 85 \mathrm{~dB}(\mathrm{~A})$. This categorization is based on EU regulations (European council 2003) concerning damage-associated noise: the recommendation to provide hearing protection facilities when the daily noise exposure level is equal or above $80 \mathrm{~dB}(\mathrm{~A})$ and the obligation that noise protection devices are used for $85 \mathrm{~dB}(\mathrm{~A})$ or more. 


\section{Statistical methods}

The primary analysis aimed at testing if the reporting was different between cases and controls; to achieve this aim, we regressed the self-reported noise exposure at work (response, dependent variable) on the expert rating of the noise levels and on case-control status (explanatory, independent variables), using the logistic model. We tested if other variables: gender, age at interview (participant below 50 years old compared with those aged 50 years or more), time elapsed between job and interview (distant jobs had terminated more than 5 years before the interview compared with recent jobs which extended into or started during this 5-year period), and presence or absence of participants hearing impairment influenced the reporting. Likelihood ratio tests of the interaction terms were used with exposure either categorized in 4 levels $(<77,77-79,80-84, \geq 85 \mathrm{~dB}(\mathrm{~A}))$ or truncated, so that exposures up to $79 \mathrm{~dB}(A)$ were set at 0 , and exposures increased by 1 unit for each additional $d B(A)$. The linear scale was analysed by analogy with the German study, while the categorical scale was chosen to explore the full range of noise levels, including levels below $80 \mathrm{~dB}$. We analysed the reporting of the complete job history (i.e. individual jobs separately), reporting of the loudest (as assessed by the expert), longest, and last job, and reporting of the screening question: “Were you ever exposed to loud noise at work?" which was compared to the loudest level of exposure of the individual. The latter comparison was considered most informative about the variable "ever/never exposed at work" used in epidemiological analyses of risk. When participants had several loudest or several longest jobs, the longest of the equally loudest jobs was chosen for the loudest and the loudest for the equally longest. In stratified analyses, we measured the capacity of the model to discriminate the subjects who reported exposure versus the others with the area under the receiver operating characteristics (ROC) curve and we also computed the expert rated exposure at which the probability of reporting exposure was above 0.5.The Kappa coefficient, which quantifies the extent of agreement beyond the expected level of agreement by chance alone (Kappa coefficients range from 1 = perfect agreement; to $-1=$ perfect disagreement), was reported (Feuerman and Miller 2008; Landis and Koch 1977); this coefficient is known to be influenced by the exposure distribution. 
Then we characterized the classification produced by the self-reports of occupational noise exposures considering that the expert rating was the "gold standard" i.e. the reference. The main focus was misclassification in relation to the imperfect memory or subjective sense of the participants. To characterise this classification scheme, the sensitivity, specificity, positive predictive value (PPV), negative predictive value (NPV) and the observed agreement were computed for noise level evaluated by the expert as equal or above $77 \mathrm{~dB}(\mathrm{~A}), 80 \mathrm{~dB}(\mathrm{~A})$, and $85 \mathrm{~dB}(\mathrm{~A})$. Values of a-priori interest $80 \mathrm{~dB}(\mathrm{~A})$ and $85 \mathrm{~dB}(\mathrm{~A})$ had been defined in the study protocol, whereas $77 \mathrm{~dB}(\mathrm{~A})$ was chosen to cover a wider range of exposure levels. The expert rating of level of noise exposure was considered as the reference. In this framework, among all jobs rated by the expert as with noise exposure, sensitivity is the proportion of jobs reported by the participant as job with noise exposure. Similarly, specificity is the proportion of jobs reported by the participant as job without noise exposure among all jobs rated by the expert as job without noise exposure. PPV is the proportion of jobs rated by the expert as with noise exposure among all jobs reported by the participant to be exposed to noise, while NPV is the proportion of jobs rated by the expert not to be exposed to noise among all jobs reported by the participant not to be exposed to noise. Finally, the observed agreement is the proportion of jobs reported by the participant and also rated by the expert as job with noise exposure together with jobs reported by the participant and also rated by the expert as job without noise exposure among all jobs.

Finally, the crude odds ratio (OR) of the association between acoustic neuroma and self-reported noise exposure was compared to the ORs obtained with the exposure calibrated for misclassification using sensitivity and specificity at $80 \mathrm{~dB}(\mathrm{~A})$ (Lash et al. 2009). Analyses were conducted using Stata and the Excel spreadsheet of Lash, Fox and Fink (2010).

\section{RESULTS}

339 persons were asked detailed questions on their loud noise exposure during the interview. Of these, 2 cases were excluded who ultimately turned out to have a trigeminal nerve sheath tumour or a 
meningioma respectively, 5 cases were excluded who had a date of diagnosis which, upon checking, was before the period of inclusion in our study, and 4 persons were excluded who had never worked.

A total of 328 participants were included in this validation study, 111 cases and 217 controls. Exposure to loud occupational noise at least one year before the reference date was reported by more cases (36\%) than controls (24\%) (Table 1). Among those who reported a professional noise exposure, only 9 cases (23\%) and 17 controls (32\%) reported provision of hearing protection. At interview, almost all cases (95\%) declared "hearing symptoms", hearing loss alone or in combination with tinnitus, in comparison to $36 \%$ of controls who reported not having normal hearing. Men (21\%) reported more exposure to noise than women (8\%) (not shown in tables).

Table 2 presents the characteristics of the job periods in cases and controls. 1006 different job periods, reported in occupational calendars by the 328 participants were analyzed. Cases reported a total of 336 job periods ( 3.0 job periods per person on average, median $=3$ ) and controls, 670 job periods (3.1 job periods per person on average, median=3). The number of job periods per person varied up to 10 , with $36 \%$ with more than 3 job periods. The within subject correlation of job exposures did not appear to influence the association between self-reported and expert assignment of noise exposure (data not shown).

The expert classified $78 \%$ of the job periods as a low level $(<80 \mathrm{~dB}(\mathrm{~A}) / 8 \mathrm{~h}), 14 \%$ as a medium level (80$84 \mathrm{~dB}(\mathrm{~A}) / 8 \mathrm{~h})$ and $8 \%$ as high level ( $\geq 85 \mathrm{~dB}(\mathrm{~A}) / 8 \mathrm{~h})$; she classified 80 cases' job periods ( $24 \%$ ) as medium or high level ( $\geq 80 \mathrm{~dB}(\mathrm{~A}) / 8 \mathrm{~h}$ ), compared to 137 for controls (20\%). Detailed analyses show that the mean noise level assessed by the expert in jobs reported as exposed was $80.2 \mathrm{~dB}(\mathrm{~A})$ with a Standard Deviation (SD) of $5.5 \mathrm{~dB}(\mathrm{~A})$, and it was $74.0 \mathrm{~dB}(\mathrm{~A})(\mathrm{SD}=4.7 \mathrm{~dB}(\mathrm{~A})$ ) in jobs reported as unexposed (not shown in Table 2). The expert assessments resulted in 202 participants (62\%) never exposed to occupational noise louder than $76 \mathrm{~dB}(\mathrm{~A})$, and 47 participants (14\%) with at least one job period exposed to $85 \mathrm{~dB}(\mathrm{~A})$ or more (not shown in Table 2). 
Cases reported being exposed to noise in 65 (19\%) out of their 336 job periods, whereas controls reported being exposed in 90 (13\%) out of their 670 job periods (Table 2). About $65 \%$ of the job periods of cases and controls ended more than five years before interview, and jobs held more than 5 years in the past were noisier than jobs held in the recent period (27\% compared to $12 \%$ at expert assessed noise level of $80 \mathrm{~dB}(\mathrm{~A})$ or higher, data not shown).

The association between the self-reports of noise exposure and the rating of the noise level of the specific job by the expert was different between cases and controls. Cases were more likely to report that they had been exposed to noise than controls, when they had been exposed - according to the experts - to noise levels of $85 \mathrm{~dB}(\mathrm{~A})$ or higher (Figure 1, Panel A). In the logistic model, the test of a difference between cases and controls produced p-values of 0.04 (when exposure was categorized) and 0.01 (when linear exposure levels were used) for the reporting of individual jobs (Table 3). The difference between cases and controls was also reflected in the cases higher area under the ROC curve (cases ROC area: 0.78 , controls ROC area: 0.71 ), and in the cases lower expert assessed noise level equal or above which the probability of reporting exposure was 0.5 or higher (cases level: $84 \mathrm{~dB}(\mathrm{~A})$, controls level: $87 \mathrm{~dB}(\mathrm{~A})$ ) (Table 3). Misclassification of individual jobs was therefore larger for controls than for cases: the controls did not report as often exposure when they were exposed according to the expert assessment, as cases did. Similar results were observed for the loudest, the longest and the last job, but the differences between cases and controls were not significant.

The difference between cases and controls was attenuated and not significant when the answer to the screening question "Were you ever exposed to loud noise at work?" was compared to lifetime ever exposure according to expert assessment (Figure 1, Panel A and Table 3). Cases and controls showed the same ROC Area (cases ROC area: 0.80 , controls ROC area: 0.81 ) and the same Kappa (0.58 for both cases and controls) (Table 3, Appendix Figure 1).

The participant's gender did not show a consistent influence on the association between self-report and expert estimates, adjusted for case-control status ( $p$-values $=0.4$ in the model with noise 
categories and 0.04 in the model with the continuous noise variable). Older participants reported more exposures than younger ones ( $p$-values $=0.02$ in the model with noise categories and 0.06 in the model with the continuous noise variable), and distant jobs were less reported as exposed than recent jobs, for the same expert noise evaluation ( $p$-values $=0.08$ in the model with noise categories and $p$-values $=0.01$ in the model with the continuous noise variable). The difference between cases and controls persisted within gender and age groups, and for distant and recent jobs (data not shown). Persons affected by tinnitus ( $\mathrm{N}=70$ ) did not appear to be able to evaluate their exposure to noise, but the numbers were very small (data not shown). In contrast, the report of people with normal hearing $(\mathrm{N}=$ 418) was similar to the report of people solely affected by hearing loss ( $N=219)$ after adjustment for case-control status (data not shown).

Table 4 presents sensitivity, specificity, PPV, NPV, and observed agreement of self-reports of noise exposure at work using the question "Were you ever exposed to loud noise at work? In which job?", when compared to the expert rating of noise level categorized into dichotomous exposure at 77,80 , and $85 \mathrm{~dB}(\mathrm{~A})$. Sensitivity was always higher and specificity very slightly lower for cases than for controls. The observed agreement of the reporting of individual jobs was nearly the same for cases as for controls. Considering the reporting of the loudest job, there was slight variation: generally, sensitivity was higher and specificity lower than when individual jobs were considered. When the reporting of lifetime ever exposure at work was compared to the exposure of the lifetime loudest job, according to expert assessment, the sensitivity of the self-reports was even higher.

Estimates of the crude ORs using different methods of assessing exposure are presented in Table 5. Self-reported exposure to ever loud occupational noise produced an OR of 1.7 (95\% Cl 1.1-2.9). The self-reported exposure calibrated by using sensitivity and specificity computed in Table 4 for cases and controls produced ORs of 1.3 for $80 \mathrm{~dB}(\mathrm{~A})$. In comparison, expert evaluation of noise levels of $\geq 80$ $d B(A)$ versus lower exposures produced an OR of $1.5(95 \% \mathrm{Cl} 0.9-2.5)$. 


\section{DISCUSSION}

In this validation study in France on self-reported noise exposure with 328 participants, we found that acoustic neuroma cases reported the loud noise exposures of individual jobs differently than controls, when compared with the expert ratings of noise levels. Cases reported closer to the expert for the highest expert assessed exposure levels. The difference between cases and controls was not significant when lifetime ever exposure was analyzed. Considering self-reporting of exposure as a way to classify exposure, participants' reporting of a loud noise exposure agreed with the expert-evaluated noise level of $80 \mathrm{~dB}(\mathrm{~A})$ or more in more than $81 \%$ of the jobs. Cases had higher sensitivity in their declarations of individual job exposure. About half of the $70 \%$ observed increased risk between self-reported lifetime noise exposure and acoustic neuroma $(O R=1.7$ versus $O R=1.3)$ may be attributable to the reporting differences between cases and controls, using the expert noise ratings as reference. There seemed to be under reporting of noise exposure among controls.

The human ear can perceive a wide range of sound pressure; and frequencies ranging from about 20 $\mathrm{Hz}$ to $20,000 \mathrm{~Hz}$ are perceptible by humans (Davies et al. 2013). The response of the human ear to sound is dependent on the frequency and the amplitude of the sound. The peak sensitivity is around $4000 \mathrm{~Hz}$ that corresponds to the resonance of the ear canal. Hearing low frequencies is usually more difficult than hearing high ones; below $30 \mathrm{~Hz}$ sounds are very hard to distinguish. The level at which a sound is perceived as noise is person dependent. Sound levels above $80 \mathrm{~dB}(\mathrm{~A})$ may cause trauma to stereocilia of the cochlear structure in the inner ear, which give rise to irreversible hearing loss. The louder the sound, the shorter the amount of time it takes for noise-induced hearing loss to happen (Ising and Kruppa 2004; Pourbakht and Yamasoba 2003; Rubak et al. 2006; Seixas et al. 2012). Sounds of less than $80 \mathrm{~dB}(\mathrm{~A})$, even after long exposure, are unlikely to cause hearing loss. Prolonged noise exposure can cause annoyance, stress, sleep disturbance, adverse cardiovascular effects, and hypertension (Basner et al. 2014). It can also interfere with communication, divert attention and increase workplace accident rates. Therefore, a fair evaluation of the loudest job period is essential to assess the hazard due to noise for noise-induced hearing loss or for a disease with the similar 
pathophysiological mechanism, as hypothesized for acoustic neuroma (Hamernik et al. 1984; Hours et al. 2009; Lesser and Pollak 1990; Schlehofer et al. 2007; Van Campen et al. 2002).

Better reporting might be due to better recall and / or better identification of noise. Hearing loss in acoustic neuroma cases is mostly unilateral, except for the small number of those with bilateral tumors of whom there was none in this dataset. As noise related symptoms and hearing loss are common early symptoms of acoustic neuroma, the issue of noise exposure is conventionally raised early in the course of the patient diagnostics, in parallel with the hearing deficiency tests. This could have contributed to the observation that cases reported their exposures closer to the expert evaluation in the job-by-job reporting. Consequently, differential misclassification or recall bias might have occurred, whereby the reporting of cases is different from that of controls. Our data supports this explanation, as the ROC curve and the accuracies for specific $\mathrm{dB}(\mathrm{A})$ levels were higher for cases than controls.

When the loudest job was considered, the agreement increased, a result also seen in the German validation study, showing that experiences of higher exposures are better reported.

The proportion of men working in noisy areas was higher, as in other studies (European Foundation for the Improvement of Living and Working Conditions 2013; Le et al. 2017); this would not explain the slight gender difference. It is, however, possible that women react differently to sound and that some of them report an exposure at a lower noise exposure than men. Given the size of the study, the diversity and gender imbalance of jobs, the low prevalence of exposure among women, and the occasional reporting of the participant gender in the job description (eg institutrice, ouvrier), it was not possible to explore this aspect more in this dataset, but it may deserve further investigation.

Older participants had slightly higher agreement with the expert rating, compared to younger participants. One explanation might be, that, with increasing age (above 50 years), presbyacusis is also increasing, which is associated with higher annoyance from loud noise. Age-related hearing loss is characterized by loss of high-frequency hearing perception, decreasing sound perception threshold but an increase in pain perception threshold sounds. 
There is no ideal solution to estimate noise exposure when the only available data are, on one hand retrospective recall by individuals, and on the other an expert-opinion approach or otherwise derived Job Exposure Matrix (e.g. from noise measurement surveys). In occupational epidemiology, exposure assessment has traditionally been based on measurements, self-reports, on expert assessment, on job exposure matrices or on mixed approaches (McGuire et al. 1998; Money et al. 2016; Teschke et al. 2002). Expert assessments are far from equivalent to measurements, but measurements were not available in our context of evaluation of noise exposures in jobs held a long time in the past. The validity of the different exposure assessement approaches depends on the exposure investigated (Friesen et al. 2011; Friesen et al. 2008; Money et al. 2016). While individuals may be biased in their recall, expert opinion cannot account for the variation between work environments having identical job titles (Bhatti et al. 2011; McGuire et al. 1998). Having access to both estimates provides an opportunity to test for systematic case-control differences in recall by using expert evaluation as a common reference. In our study, because noise can be perceived, it was expected that self-reports could provide a good estimate of the exposure, in contrast to other, less obvious exposures such as asbestos (Hardt et al. 2014). No French job-exposure matrix was readily available for this French study. However, the expert, which evaluated the occupational noise exposures for this study, assesses routinely lesional noise exposure for employees requesting recognition of their hearing loss as an occupational disease in daily clinical practice. This adds up to the expertise of UMRESTTE on industrial noise exposure assessment and provides a scale of reference of noise exposures. We believed our expert was well calibrated, so on average, her assessments were correct, but true noise levels may have been more variable than her evaluations. Hence, the error structure of the expert assessment compared to the unknown true noise levels is of Berkson type. This study has been performed similarly to the validation study of German participants of Interphone (Schlaefer et al. 2009), with some methodological modifications. In the German noise validation study, the evaluation of exposures was based on the databases of workplace noise measurements of the Swiss SUVA (Schweizerische Unfallversicherung - Swiss Accident Insurance 
Fund) and the German BGIA (Berufsgenossenschaftliches Institut für Arbeitsschutz - Research Institute for Workers' Protection of the German Social Accident Insurance).

Comparing results of noise validation studies shows both similarities and differences. In the German study, cases had a higher sensitivity than controls for the cutpoint of $80 \mathrm{~dB}(\mathrm{~A})$ (Schlaefer et al. 2009). In a Swedish study using a Swedish job exposure matrix for occupational noise as reference for the exposure assessment, sensitivity was $68 \%$ in cases and $61 \%$ in controls at $85 \mathrm{~dB}(\mathrm{~A})$, while specificity was $86 \%$, similar in cases and controls (Fisher et al. 2014; Sjöström et al. 2013). Therefore, cases of the Swedish study had a lower sensitivity and specificity than the French study cases, while controls in the Swedish study appeared to report similarly to controls of the French study.

The analysis of the self-reported exposure in the French INTERPHONE data suggested an association between loud occupational noise exposure and acoustic neuroma (Hours et al. 2009). However, upon calibration for the level of differential misclassification and assuming expert rating was the reference, the strength of the association decreased by half, i.e. the $70 \%$ increase in risk of the crude analyses was attenuated to about $30-40 \%$.

This study has several limitations. Although our results were similar to those of a Swedish and a German study, noise reporting appeared to depend on subject specific characteristics. The expert could not evaluate single brief exposure to high noise level either, for example accidental exposures, although these might have influenced the reporting of participants. Frequent high exposures may lead to the use of hearing protection which in turn would diminish the exposure (Stucken and Hong 2014). Neither JEM based evaluations, nor expert evaluations are real gold standards of noise measurements. Analyses on larger datasets using these complementary methods of exposure assessment as alloyed gold standard could provide further insight. Further research could also consider validation of other metric of noise exposures used in epidemiological analyses, such as duration or intensity of exposure, and evaluate if findings can be generalized to other settings. 
Occupational noise exposure and subsequent hearing loss is a severe burden in industrialized countries (Stucken and Hong 2014). However, measurements of exposure in the frame of epidemiologic observational studies remains difficult or even impossible. Therefore, we evaluated the validity of selfreported levels of occupational noise exposure. In conclusion, despite its limitations, we found in this validation study of self-reported noise exposure of the French Interphone participants that selfreporting of loud noise exposure was a good proxy for expert evaluation of occupational noise exposures. Albeit being a good proxy however, if the expert rating is considered the reference, recall differences between cases and controls in self-reported noise exposure may explain half of the observed modest association of a 70\% risk increase between noise exposure and acoustic neuroma risk. 


\section{References}

Adelman S (1983) Identification of acoustic neuroma in noise-exposed workers. Scandinavian Audiology 12(4):247-250 doi:10.3109/01050398309044427

Ahmed HO, Dennis JH, Ballal SG (2004) The accuracy of self-reported high noise exposure level and hearing loss in a working population in Eastern Saudi Arabia. Int J Hyg Environ Health 207(3):227-34 doi:10.1078/1438-4639-00291

Basner M, et al. (2014) Auditory and non-auditory effects of noise on health. Lancet 383(9925):132532 doi:10.1016/S0140-6736(13)61613-X

Bhatti P, Stewart PA, Linet MS, Blair A, Inskip PD, Rajaraman P (2011) Comparison of occupational exposure assessment methods in a case-control study of lead, genetic susceptibility and risk of adult brain tumours. Occup Environ Med 68(1):4-9 doi:10.1136/oem.2009.048132

Cardis E, et al. (2007) The INTERPHONE study: design, epidemiological methods, and description of the study population. European journal of epidemiology 22(9):647-64

Davies WJ, et al. (2013) Perception of soundscapes: An interdisciplinary approach. Applied Acoustics 74(2):224-231 doi:http://dx.doi.org/10.1016/i.apacoust.2012.05.010

Edwards CG, Schwartzbaum JA, Lonn S, Ahlbom A, Feychting M (2006) Exposure to loud noise and risk of acoustic neuroma. Am J Epidemiol 163(4):327-333

Edwards CG, et al. (2007) Occupational noise exposure and risk of acoustic neuroma. American journal of epidemiology 166(11):1252-8 doi:kwm217 [pii]

10.1093/aje/kwm217 [doi]

European council (2003) Directive 2003/10/EC of the european parliament and of the council of 6 February 2003, on the minimum health and safety requirements regarding the exposure of workers to the risks arising from physical agents (noise)

European Foundation for the Improvement of Living and Working Conditions (2013) Working conditions and occupational risks: SUMER 2010. Report of the European Foundation for the Improvement of Living and Working Conditions, 2013.

Feuerman M, Miller AR (2008) Relationships between statistical measures of agreement: sensitivity, specificity and kappa. J Eval Clin Pract 14(5):930-3 doi:10.1111/j.1365-2753.2008.00984.x

Fisher EW, Parikh AA, Harcourt JP, Wright A (1994) The burden of screening for acoustic neuroma: asymmetric otological symptoms in the ENT clinic. Clinical otolaryngology and allied sciences 19(1):19-21

Fisher JL, et al. (2014) Loud noise exposure and acoustic neuroma. Am J Epidemiol 180(1):58-67 doi:10.1093/aje/kwu081

Friesen MC, et al. (2011) Validity and reliability of exposure assessors' ratings of exposure intensity by type of occupational questionnaire and type of rater. Ann Occup Hyg 55(6):601-11 doi:10.1093/annhyg/mer019

Friesen MC, Davies HW, Ostry A, Teschke K, Demers PA (2008) Impact of expert versus measurementbased occupational noise exposure estimates on exposure-response relationships. Int Arch Occup Environ Health 81(7):837-44 doi:10.1007/s00420-007-0274-0

Hamernik RP, Turrentine G, Roberto M, Salvi R, Henderson D (1984) Anatomical correlates of impulse noise-induced mechanical damage in the cochlea. Hearing research 13(3):229-47

Hardt JS, Vermeulen R, Peters S, Kromhout H, McLaughlin JR, Demers PA (2014) A comparison of exposure assessment approaches: lung cancer and occupational asbestos exposure in a population-based case-control study. Occup Environ Med 71(4):282-8 doi:10.1136/oemed2013-101735

Hormozi M, Ansari-Moghaddam A, Mirzaei R, Dehghan Haghighi J, Eftekharian F (2017) The risk of hearing loss associated with occupational exposure to organic solvents mixture with and without concurrent noise exposure: A systematic review and meta-analysis. Int J Occup Med Environ Health 30(4):521-535 doi:10.13075/ijomeh.1896.01024 
Hours M, et al. (2009) Can loud noise cause acoustic neuroma? Analysis of the INTERPHONE study in France. Occupational and environmental medicine 66(7):480-6 doi:oem.2008.042101 [pii]

10.1136/oem.2008.042101 [doi]

Hours M, et al. (2007) [Cell Phones and Risk of brain and acoustic nerve tumours: the French INTERPHONE case-control study.]. RevEpidemiolSant, Publique [Epub ahead of print] French.

Ising H, Kruppa B (2004) Health effects caused by noise: evidence in the literature from the past 25 years. Noise \& health 6(22):5-13

Landis JR, Koch GG (1977) The measurement of observer agreement for categorical data. Biometrics 33:159-174

Lash TL, Fox MP, Fink AK (2009) Applying Quantitative Bias Analysis to Epidemiologic Data. Springer New York

Lash TL, Fox MP, MacLehose RF, Maldonado G, McCandless LC, Greenland S (2014) Good practices for quantitative bias analysis. Int J Epidemiol 43(6):1969-85 doi:10.1093/ije/dyu149

Le TN, Straatman LV, Lea J, Westerberg B (2017) Current insights in noise-induced hearing loss: a literature review of the underlying mechanism, pathophysiology, asymmetry, and management options. J Otolaryngol Head Neck Surg 46(1):41 doi:10.1186/s40463-017-0219-x

Lesser TH, Pollak A (1990) Acoustic schwannoma of traumatic origin? A temporal bone study. The Journal of laryngology and otology 104(3):270-4

Lie A, et al. (2016) Occupational noise exposure and hearing: a systematic review. Int Arch Occup Environ Health 89(3):351-72 doi:10.1007/s00420-015-1083-5

McGuire V, Nelson LM, Koepsell TD, Checkoway H, Longstreth WT, Jr. (1998) Assessment of occupational exposures in community-based case-control studies. Annu Rev Public Health 19:35-53 doi:10.1146/annurev.publhealth.19.1.35

Miller MH, Doyle TJ, Geier SR (1981) Acoustic neurinoma in a population of noise exposed workers. Laryngoscope 91(3):363-71

Money A, Robinson C, Agius R, de Vocht F (2016) Wishful Thinking? Inside the Black Box of Exposure Assessment. Ann Occup Hyg 60(4):421-31 doi:10.1093/annhyg/mev098

Pourbakht A, Yamasoba T (2003) Cochlear damage caused by continuous and intermittent noise exposure. Hearing research 178(1-2):70-8

Preston-Martin S, Thomas DC, Wright WE, Henderson BE (1989) Noise trauma in the aetiology of acoustic neuromas in men in Los Angeles County, 1978-1985. Br J Cancer 59(5):783-786

Rubak T, Kock SA, Koefoed-Nielsen B, Bonde JP, Kolstad HA (2006) The risk of noise-induced hearing loss in the Danish workforce. Noise \& health 8(31):80-7

Schlaefer K, Schlehofer B, Schuz J (2009) Validity of self-reported occupational noise exposure. Eur J Epidemiol 24(8):469-75 doi:10.1007/s10654-009-9357-4

Schlehofer B, et al. (2007) Environmental risk factors for sporadic acoustic neuroma (Interphone Study Group, Germany). Eur J Cancer 43(11):1741-7

Seixas NS, et al. (2012) 10-Year prospective study of noise exposure and hearing damage among construction workers. Occupational and environmental medicine 69(9):643-50 doi:10.1136/oemed-2011-100578

Sjöström M, et al. (2013) A job-exposure matrix for occupational noise: development and validation. Ann Occup Hyg 57(6):774-83 doi:10.1093/annhyg/met001

Stucken EZ, Hong RS (2014) Noise-induced hearing loss: an occupational medicine perspective. Curr Opin Otolaryngol Head Neck Surg 22(5):388-93 doi:10.1097/MOO.0000000000000079

Teschke K, et al. (2002) Occupational exposure assessment in case-control studies: opportunities for improvement. Occup Environ Med 59(9):575-593

Van Campen LE, Murphy WJ, Franks JR, Mathias PI, Toraason MA (2002) Oxidative DNA damage is associated with intense noise exposure in the rat. Hearing research 164(1-2):29-38 


\section{Figure caption}

Fig. $1 \mathrm{Graph}$ of the percentage of self-reported noise exposure as a function of expert noise evaluation for different groups of subjects or job characteristics, validation study of self-reported noise, French Interphone study, 2000-2004.

Panel a: individual jobs exposures (black) and lifetime exposure (grey) for cases (solid line) and controls (dashed line).

Panel b: individual jobs exposure for men (grey dashed line) and women (black dashed lines), for participants younger than 50 years (dotted grey line) and older (dotted black line), for jobs held in the recent past (dots and dashed alternating grey) and in the distant past (dots and dashed alternating black) 


\section{TABLES}

Table 1: Selected characteristics of cases and controls in the validation study of self-reported noise, French Interphone Study, 2000-2004.

\begin{tabular}{|c|c|c|}
\hline Characteristics & $\begin{array}{l}\text { Cases } \\
n=111(100 \%)\end{array}$ & $\begin{array}{l}\text { Controls } \\
n=217(100 \%)\end{array}$ \\
\hline \multicolumn{3}{|l|}{ Gender } \\
\hline Men & $57(51 \%)$ & $102(47 \%)$ \\
\hline Women & $54(49 \%)$ & $115(53 \%)$ \\
\hline \multicolumn{3}{|l|}{ Age at interview } \\
\hline$<40$ years & $21(19 \%)$ & $31(14 \%)$ \\
\hline $40-49$ years & $42(38 \%)$ & $82(38 \%)$ \\
\hline$>50$ years & $48(43 \%)$ & $104(48 \%)$ \\
\hline \multicolumn{3}{|l|}{ Hearing symptoms } \\
\hline Normal hearing & $5(5 \%)$ & $139(64 \%)$ \\
\hline Hearing loss without tinnitus & $28(25 \%)$ & $41(19 \%)$ \\
\hline Tinnitus without hearing loss & $5(5 \%)$ & $18(8 \%)$ \\
\hline Both symptoms : tinnitus and hearing loss & $73(66 \%)$ & $19(9 \%)$ \\
\hline \multicolumn{3}{|l|}{ Self reported exposure to loud noise at work } \\
\hline Ever & $40(36 \%)$ & $53(24 \%)$ \\
\hline Never & $71(64 \%)$ & $164(76 \%)$ \\
\hline Don't know & $0(0 \%)$ & $1(2 \%)$ \\
\hline \multicolumn{3}{|l|}{ Ever had protective equipment at work ${ }^{a}-$} \\
\hline Yes & $9(23 \%)$ & $17(32 \%)$ \\
\hline No & $31(78 \%)$ & $35(66 \%)$ \\
\hline Don't know & $0(0 \%)$ & $1(2 \%)$ \\
\hline
\end{tabular}

a $\%$ out of those who reported exposure to loud noise at work. 
Table 2: Description of job periods, according to case-control status, validation study of self-reported noise, French Interphone Study, 2000-2004.

\begin{tabular}{|c|c|c|c|}
\hline \multirow{2}{*}{ Job periods } & Cases' job periods & $\begin{array}{c}\text { Controls' job } \\
\text { periods }\end{array}$ & All job periods \\
\hline & $n=336(100 \%)$ & $n=670(100 \%)$ & $\begin{array}{l}n=1006 \\
(100 \%)\end{array}$ \\
\hline \multicolumn{4}{|l|}{ Self-reported exposure at work } \\
\hline Number of job periods with loud noise & 65 (19\%) & $90(13 \%)$ & $155(15 \%)$ \\
\hline Number of job periods without loud noise & $271(81 \%)$ & $580(87 \%)$ & $851(85 \%)$ \\
\hline \multicolumn{4}{|l|}{ Noise level assignment by the expert } \\
\hline$<80 \mathrm{~dB}(\mathrm{~A}) / 8 \mathrm{~h}$ & $256(76 \%)$ & $533(80 \%)$ & $789(78 \%)$ \\
\hline $80-84 \mathrm{~dB}(\mathrm{~A}) / 8 \mathrm{~h}$ & $48(14 \%)$ & $92(14 \%)$ & $140(14 \%)$ \\
\hline$\geq 85 \mathrm{~dB}(\mathrm{~A}) / 8 \mathrm{~h}$ & $32(10 \%)$ & $45(7 \%)$ & $77(8 \%)$ \\
\hline \multicolumn{4}{|l|}{ Job periods in distant and recent past } \\
\hline Ended more than 5 years before interview & $214(64 \%)$ & $433(65 \%)$ & 647 (64\%) \\
\hline $\begin{array}{l}\text { Extended in/or occurred during the last } 5 \text { years before } \\
\text { interview }\end{array}$ & $122(36 \%)$ & $237(35 \%)$ & $359(36 \%)$ \\
\hline
\end{tabular}




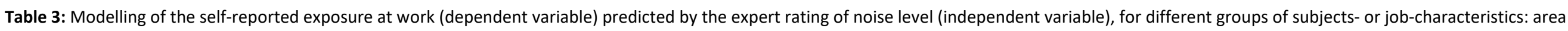


study, 2000-2004.

\begin{tabular}{|c|c|c|c|c|c|c|c|c|c|c|}
\hline & $\mathrm{N}$ & Roc $_{\text {area }}{ }^{a}$ & $\begin{array}{l}\text { Noise level equal or above } \\
\text { which the probability of } \\
\text { reporting exposure is } 0.5^{\text {a }} \\
\text { Cases }\end{array}$ & Kappa ${ }^{b}$ & $\mathrm{~N}$ & Roc $_{\text {area }}{ }^{a}$ & $\begin{array}{c}\text { Noise level equal or above } \\
\text { which the probability of } \\
\text { reporting exposure is } 0.5^{\text {a }} \\
\text { Controls }\end{array}$ & Kappab & $\begin{array}{l}P- \\
\text { value }^{c,}\end{array}$ & $\begin{array}{l}\text { P- } \\
\text { value }_{d}^{a,}\end{array}$ \\
\hline Reporting of individual jobs & 336 & 0.78 & $84 \mathrm{~dB}(\mathrm{~A})$ & 0.48 & 670 & 0.71 & $87 \mathrm{~dB}(\mathrm{~A})$ & 0.33 & 0.04 & 0.01 \\
\hline Reporting of loudest job & 111 & 0.80 & $84 \mathrm{~dB}(\mathrm{~A})$ & 0.54 & 217 & 0.75 & $86 \mathrm{~dB}(\mathrm{~A})$ & 0.44 & 0.17 & 0.09 \\
\hline Reporting of longest job & 111 & 0.76 & $83 \mathrm{~dB}(\mathrm{~A})$ & 0.53 & 217 & 0.70 & $85 \mathrm{~dB}(\mathrm{~A})$ & 0.40 & 0.32 & 0.11 \\
\hline Reporting of last job & 111 & 0.81 & $82 \mathrm{~dB}(\mathrm{~A})$ & 0.65 & 217 & 0.62 & $84 \mathrm{~dB}(\mathrm{~A})$ & 0.26 & 0.28 & 0.24 \\
\hline $\begin{array}{l}\text { Reporting of lifetime ever exposure } \\
\text { compared to exposure of loudest job }\end{array}$ & 111 & 0.80 & $82 \mathrm{~dB}(\mathrm{~A})$ & 0.58 & 217 & 0.81 & $84 \mathrm{~dB}(\mathrm{~A})$ & 0.58 & 0.09 & 0.12 \\
\hline Gender & & & Men & & & & Women & & & \\
\hline Reporting of individual job & 549 & 0.74 & $86 \mathrm{~dB}(\mathrm{~A})$ & 0.36 & 457 & 0.65 & $85 \mathrm{~dB}(\mathrm{~A})$ & 0.30 & 0.42 & 0.04 \\
\hline Age of participant & & & $<50$ years old & & & & $\geq 50$ years & & & \\
\hline Reporting of individual job & 528 & 0.70 & NA & 0.33 & 478 & 0.77 & $85 \mathrm{~dB}(\mathrm{~A})$ & 0.50 & 0.02 & 0.06 \\
\hline Reporting of individual job & 647 & 0.76 & $86 \mathrm{~dB}(\mathrm{~A})$ & 0.38 & 359 & 0.69 & $83 \mathrm{~dB}(\mathrm{~A})$ & 0.40 & 0.08 & 0.01 \\
\hline
\end{tabular}

${ }^{a}$ Analyses based on logistic regressions with exposure up to $79 \mathrm{~dB}(\mathrm{~A})$ included at 0 , and linear increase for higher exposures.

${ }^{b}$ Kappa coefficient between self-report and expert evaluation of $80 \mathrm{~dB}(\mathrm{~A})$

${ }^{c}$ Analyses based on logistic regressions with exposure categorised in $<77,77-79,80-84$ and $\geq 85 \mathrm{~dB}(\mathrm{~A})$.

d Likelihood ratio test of the interaction terms; in the lower panel, analyses adjusted for case-control status

NA: Not available 


\begin{tabular}{|c|c|c|c|c|c|c|}
\hline & \multicolumn{2}{|c|}{$\begin{array}{l}\text { Regarded as exposed if expert rated } \\
\text { exposure }>=77 \mathrm{~dB}(\mathrm{~A}) / 8 \mathrm{~h}\end{array}$} & \multicolumn{2}{|c|}{$\begin{array}{l}\text { Regarded as exposed if expert rated } \\
\text { exposure }>=80 \mathrm{~dB}(\mathrm{~A}) / 8 \mathrm{~h}\end{array}$} & \multicolumn{2}{|c|}{$\begin{array}{c}\text { Regarded as exposed if expert ratec } \\
\text { exposure }>=85 \mathrm{~dB}(\mathrm{~A}) / 8 \mathrm{~h}\end{array}$} \\
\hline & Cases & Controls & Cases & Controls & Cases & Controls \\
\hline \multicolumn{7}{|c|}{ Job by job comparison of self-reported exposure and expert rating, all job periods ( $N=1006$ ) } \\
\hline Classification scheme' sensitivity & $43 \%$ & $32 \%$ & $54 \%$ & $37 \%$ & $75 \%$ & $40 \%$ \\
\hline Classification scheme' specificity & $93 \%$ & $94 \%$ & $91 \%$ & $93 \%$ & $87 \%$ & $89 \%$ \\
\hline Classification scheme' PPV & $77 \%$ & $70 \%$ & $66 \%$ & $56 \%$ & $37 \%$ & $20 \%$ \\
\hline Classification scheme' NPV & $76 \%$ & $77 \%$ & $86 \%$ & $85 \%$ & $97 \%$ & $95 \%$ \\
\hline Classification scheme' observed agreement & $76 \%$ & $76 \%$ & $82 \%$ & $81 \%$ & $85 \%$ & $85 \%$ \\
\hline \multicolumn{7}{|c|}{ Comparison of self-reported exposure and expert rating of loudest job ( $N=328)$} \\
\hline Classification scheme' sensitivity & $55 \%$ & $39 \%$ & $62 \%$ & $47 \%$ & $74 \%$ & $43 \%$ \\
\hline Classification scheme' specificity & $94 \%$ & $93 \%$ & $89 \%$ & $92 \%$ & $82 \%$ & $85 \%$ \\
\hline Classification scheme' PPV & $87 \%$ & $75 \%$ & $74 \%$ & $70 \%$ & $45 \%$ & $30 \%$ \\
\hline Classification scheme' NPV & $73 \%$ & $73 \%$ & $83 \%$ & $82 \%$ & $94 \%$ & $91 \%$ \\
\hline Classification scheme' observed agreement & $77 \%$ & $74 \%$ & $80 \%$ & $80 \%$ & $80 \%$ & $80 \%$ \\
\hline \multicolumn{7}{|c|}{ Comparison of self-reported lifetime exposure and expert rating of loudest job ( $N=328)$} \\
\hline Classification scheme' sensitivity & $67 \%$ & $53 \%$ & $76 \%$ & $65 \%$ & $90 \%$ & $64 \%$ \\
\hline Classification scheme' specificity & $89 \%$ & $91 \%$ & $84 \%$ & $91 \%$ & $75 \%$ & $82 \%$ \\
\hline Classification scheme' PPV & $83 \%$ & $77 \%$ & $70 \%$ & $74 \%$ & $43 \%$ & $34 \%$ \\
\hline Classification scheme' NPV & $78 \%$ & $78 \%$ & $87 \%$ & $87 \%$ & $97 \%$ & $94 \%$ \\
\hline Classification scheme' observed agreement & $79 \%$ & $78 \%$ & $81 \%$ & $84 \%$ & $77 \%$ & $79 \%$ \\
\hline
\end{tabular}


Table 5: Acoustic neuroma crude risk estimates (unmatched, unadjusted) for life-long ever exposure based on different methods for assessing or calibrating exposure, validation study of selfreported noise, French Interphone study, 2000-2004

\begin{tabular}{|c|c|c|c|c|c|c|}
\hline Type of exposure & $\begin{array}{c}\text { Exposed } \\
\text { cases } \\
(\mathrm{N})\end{array}$ & $\begin{array}{c}\text { Exposed } \\
\text { controls } \\
(\mathrm{N})\end{array}$ & $\begin{array}{c}\text { Not } \\
\text { exposed } \\
\text { cases } \\
(\mathrm{N})\end{array}$ & $\begin{array}{c}\text { Not } \\
\text { exposed } \\
\text { controls (N) }\end{array}$ & OR & $95 \% \mathrm{Cl}$ \\
\hline Self-reports & 40 & 53 & 71 & 164 & 1.7 & {$[1.1 ; 2.9]$} \\
\hline Expert evaluation, dichotomised at $80 \mathrm{~dB}(\mathrm{~A})$ & 30 & 44 & 81 & 173 & 1.5 & {$[0.9 ; 2.5]$} \\
\hline Self-reports, calibrated based on sensitivity and specificity at $80 \mathrm{~dB}(A)^{a}$ & 37.1 & 59.8 & 73.9 & 157.2 & 1.3 & {$[0.6 ; 3.1]$} \\
\hline
\end{tabular}

a Parameters for sensitivity (SE) and specificity (SP) were, for cases (+), 76\% and $84 \%$, and, for controls (-), $65 \%$ and $91 \%$, as reported in Table 4 ; calibration conducted according to the calibration method of Lash and colleagues (Lash et al, 2009) using the excel spreadsheet of Lash, Fox and Fink (chapter 6 ) (see appendix 1 for details of calculation). 